\title{
DINÂMICA MICROCLIMÁTICA E SUAS CONEXÕES COM OS SISTEMAS ATMOSFÉRICOS NAS UNIDADES DE PAISAGEM, PANTANAL DA NHECOLÂNDIA, MS: CASO DO DIA 22 A 28 DE JULHO DE 2014.
}

\author{
Heloissa Gabriela Silva Sokolowski ${ }^{1}$ \\ Ana Beatriz Brito Balieiro ${ }^{2}$ \\ Arnaldo Yoso Sakamoto $^{3}$
}

\section{RESUMO}

O clima do Pantanal sul Mato-grossense é do tipo tropical, com duas estações bem definidas, uma seca no inverno e outra chuvosa no verão. O presente estudo foi realizado nos dias 22 a 28 de Julho de 2014, com objetivo geral de contribuir para o conhecimento da dinâmica climática na área da Fazenda Firme no Pantanal da Nhecolândia em três unidades de Paisagem distintas. O procedimento adotado foi baseado na coleta de registros de medidas de temperatura, umidade relativa e precipitação automaticamente de $1 \mathrm{em} 1$ hora. Foi realizado um levantamento foto-descritivo dessas unidades, com auxilio de GPS e máquina fotográfica. Para as análises foram usados os dados da Estação Meteorológica. Por fim, o microclima registrado em cada ambiente possibilitou estabelecer que a dinâmica atmosférica, os elementos das unidades da paisagem e a ocupação podem ser condições que alteram o microclima da diferentes unidades.

PALAVRAS-CHAVE: Microclima - Paisagem - Pantanal

\section{MICROCLIMATE DYNAMICS AND CONNECTIONS TO THE ATMOSPHERIC SYSTEMS IN LANDSCAPE UNITS, WETLAND NHECOLÂNDIA, MS : DAY EVENT 22 OF 28 JULY 2014}

\section{ABSTRACT}

The climate of southern Mato Grosso Pantanal is the tropical type with two distinct seasons, a dry winter and a rainy season in summer. This study was conducted from 22 to 28 July 2014, with the overall objective of contributing to the knowledge of climate dynamics in the area of Finance Firm in

1 Acadêmica do curso pós-graduação em Geografia pela Universidade federal de Mato Grosso do Sul-geo.sokolowski@gmail.com

2 Acadêmica do curso de Geografia pela Universidade Federal de Mato Grosso do Sul geo.sokolowski@gmail.com

3 Professor do curso de Geografia da Universidade Federal de Mato Grosso do Sul arnaldosakamoto@gmail.com. 
the Pantanal of Nhecolândia in three different landscape units. The procedure adopted was based on the collection of temperature measurements records, automatically relative humidity and rainfall of 1 in 1 hour. A photo-descriptive survey was conducted of these units with GPS assistance and camera. For the analysis we used data from the Weather Station. Finally, the microclimate recorded in each environment that allowed the establishment of the atmospheric dynamics, the elements of landscape units and occupation can change the microclimate conditions of different units.

KEYWORDS: microclimate - Landscape - Pantanal

\section{DINÁMICA MICROCLIMA Y CONEXIONES A LOS SISTEMAS ATMOSFÉRICA EN UNIDADES DE PAISAJE, HUMEDAL NHECOLÂNDIA, MS : DIA DEL EVENTO 22 DE 28 DE JULIO DE 2014}

\section{RESUMEN}

El clima del sur de Mato Grosso Pantanal es del tipo tropical con dos estaciones bien diferenciadas, un invierno seco y una temporada de lluvias en verano. Este estudio se llevó a cabo entre 22 y 28 julio de 2014, con el objetivo general de contribuir al conocimiento de la dinámica del clima en el área de Finanzas Firma en el Pantanal de Nhecolândia en tres unidades de paisaje diferentes. El procedimiento adoptado se basa en la recopilación de mediciones de temperatura registros, la humedad relativa y la precipitación automáticamente de 1 en 1 hora. Una encuesta-foto descriptiva se realizó de estas unidades con la ayuda del GPS y la cámara. Para el análisis se utilizaron los datos de la estación meteorológica. Por último, el microclima registra en cada entorno que permitió el establecimiento de la dinámica atmosférica, los elementos de las unidades de paisaje y la ocupación puede cambiar las condiciones microclimáticas de diferentes unidades.

PALABRAS CLAVE: microclima - Paisaje - Pantanal

\section{INTRODUÇÃO}

Região pantaneira está localizada na parte central da América do Sul presentes no Paraguai, Bolívia e a maior parte no Brasil. Dentro do território brasileiro é conhecida simplesmente como Pantanal ou Pantanal Matogrossense por estar totalmente dentro dos estados de Mato Grosso (35,5\%) e Mato Grosso do sul ( $65,5 \%)$ na região Centro-oeste, entre os paralelos $16^{\circ}$ e $22^{\circ}$ e os meridianos $55^{\circ}$ e 58ํㅡ, com uma área total aproximada de 138.183 km². Garcia (1984 apud Brasil, 1974); (SILVA e ABDON, 1998).

A depressão pantaneira é caracterizada por enchentes anuais periódicas ocasionadas pela baixa declividade regional, sendo o Rio Paraguai o nível de base regional. O clima é do tipo tropical, com duas estações bem definidas, uma seca no inverno e outra chuvosa no verão, com média pluviométrica de 1.100 a 1.800 mm no 
planalto e de 850 a $1.100 \mathrm{~mm}$ na depressão com temperatura média de $25^{\circ} \mathrm{C}$ a $26^{\circ} \mathrm{C}$ (ALVARENGA et al; 1982 in GRADELLA et al; 2005). Assine (2003) nos coloca que o Pantanal é uma bacia sedimentar tectonicamente ativa que vem ocorrendo mudanças climáticas e tectônicas desde o Pleistocêno.

A área estudo está inserida no Pantanal da Nhecolândia, destacando seu complexo sistema de lagoas salinas, salitradas, cordilheiras, contrastando com baías e vazantes; (QUEIROZ NETO et. al., 1998), a área está localizada entre os paralelos de $19^{\circ} 04^{\prime} 33^{\prime \prime} \mathrm{S}$ e $19^{\circ} 21^{\prime} 00^{\prime \prime} \mathrm{S}$, e meridianos de $56^{\circ} 53^{\prime} 20^{\prime \prime} \mathrm{W}$ e $57^{\circ} 05^{\prime} 23^{\prime \prime} \mathrm{W}$, abrangendo uma porção de terras da Fazenda Firme.

Esta fazenda particulariza-se por apresentar de modo muito representativo 0 grande complexo paisagístico existente no Pantanal da Nhecolândia, apresentando baías, salinas, "cordilheiras", vazantes, áreas de campo com gramíneas nativas e também pastagens introduzidas.

\section{OBJETIVOS}

O objetivo geral é o de contribuir para o conhecimento da dinâmica climática na área da Fazenda Firme no Pantanal da Nhecolândia em três unidades de Paisagem distintas durante os dias 22 a 28 de Julho de 2014. Os objetivos específicos foram: (1) entender a variação da temperatura e umidade relativa em uma transeção nas diferentes paisagens; (2) analisar os fatores que propiciam a dinâmica climática desta área no determinado período; e (3) analisar a dinâmica atmosférica para estabelecer a influência na mudança do tempo com o microclima nas paisagens analisadas.

\section{MATERIAIS E MÉTODOS}

A presente pesquisa procurou utilizar a metodologia baseada na proposta de Sezerino e Monteiro (1990), de uma forma adaptada, procurando caracterizar a variação térmica nas unidades da paisagem selecionadas ao longo de um transecto e realizando-se as medidas de temperatura do ar (a 1,5 m) e da umidade relativa do ar (SEZERINO \& MONTEIRO, 1990). 
Primeiramente foram efetuados levantamentos bibliográficos em gabinete, com cunho conceitual e teórico (dando ênfase aos conceitos de clima, micro-clima, solo, vegetação e paisagem, bem como vistas no objetivo do estudo). Com o objetivo de dar continuidade às investigações microclimáticas no Pantanal da Nhecolândia, foram realizadas medidas e observações de campo em área da lagoa salina, Lagoa Salitrada e Baía.

Posteriormente, foram instalados Estações Meteorológicas nas três unidades de paisagem, realizando registros de amostragem climática utilizando as variáveis de temperatura, precipitação e umidade relativa, as medidas foram registradas automaticamente de 1 em 1 hora durante os dias 22 a 28 de Julho de 2014, e os dados foram analisado mais precisamente em três intervalos, os $09 \mathrm{~h}, 15 \mathrm{~h}$ e $21 \mathrm{~h}$ conforme padrão de análise estabelecido pela (OMM) Organização Meteorológica Mundial. Os dados foram analisados e organizados em gráficos. A circulação da atmosfera no período dos experimentos foi realizada através da leitura de cartas sinóticas da Marinha do Brasil, apoiados em imagens do satélite meteorológico GOES 12 (Infravermelho) dos dias das análises, obtidas junto ao site oficial do Instituto Nacional de Pesquisas Espaciais - CPTEC/ INPE e para localização geográfica foi utilizado GPS de navegação Garmim. Foram realizados levantamentos foto-descritivos (máquina fotográfica), para caracterização dessas unidades da paisagem.

\section{RESULTADOS}

\subsection{Descrição das paisagens}

Podemos considerar a vegetação e o uso e ocupação da área tem um fator de grande relevância na dinâmica climática, tendo em vista que "(...) a presença das formações vegetais que, já tendo sido possibilitadas pelas condições climáticas, passam a exercer - em retorno - influência sobre o clima" (Monteiro, 1999, p.17).

A descrição das paisagens nos pontos do transeto foram realizadas por meio dos levantamentos fotos-descritivos in loco, assim, os pontos de amostragem tiveram suas peculiaridades na ocupação do solo e indivíduos vegetais. Praia da lagoa Salina é uma área cercada por cordilheira, com presença de solo exposto ao redor da lagoa (Figura 1). 


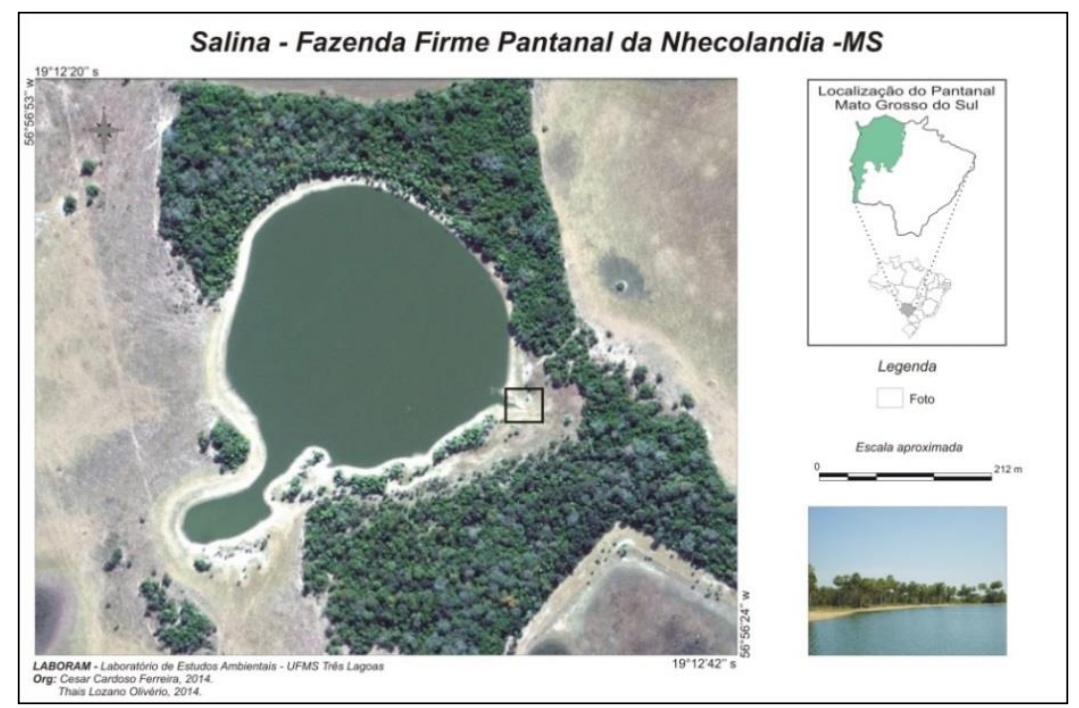

Figura 1 - Lagoa Salina

Lagoa Salitrada é caracterizada como um local que apresenta cobertura vegetal rala (pastagem), a área tem sua particularidade no sentido de que está localizada em um ambiente totalmente aberto onde não há presença de indivíduos vegetais significativos e por isso recebe insolação direta a partir do início do dia até ao seu final. $O$ registro foi realizado na margem da lagoa. (Figura 2)

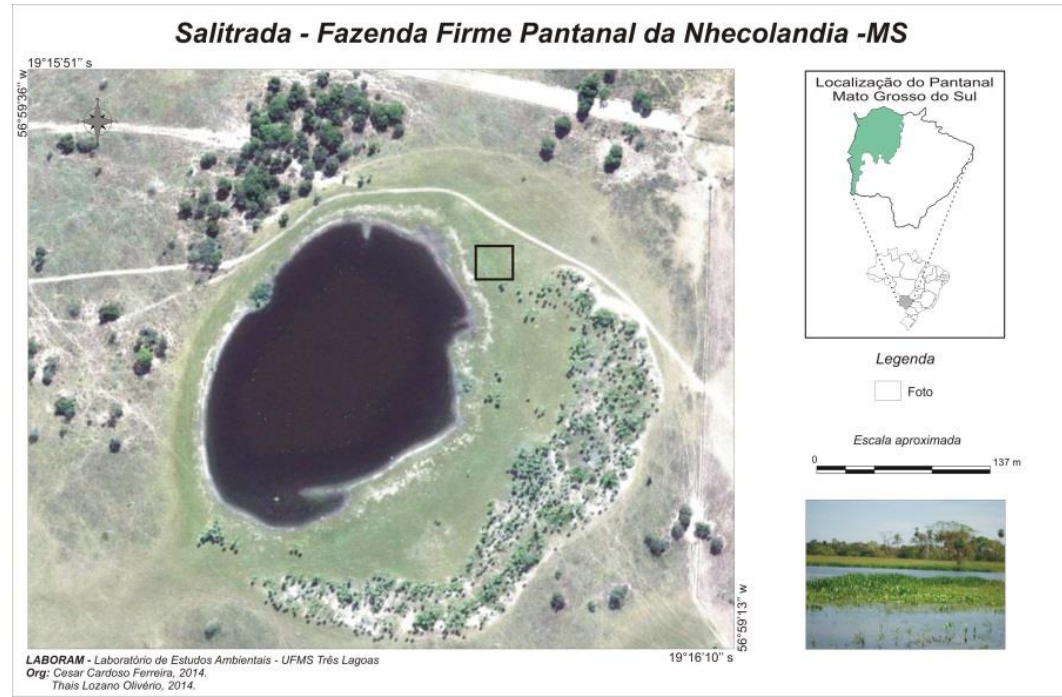

Figura 2 - Lagoa Salitrada

A Baía esta localizada próxima à sede da fazenda, nota-se a presença de carandás e gramíneas. Destacando que o alto índice de plantas aquáticas ao entorno da lagoa devido ao alagamento frequente das chuvas (período de cheia) Figura 3. 


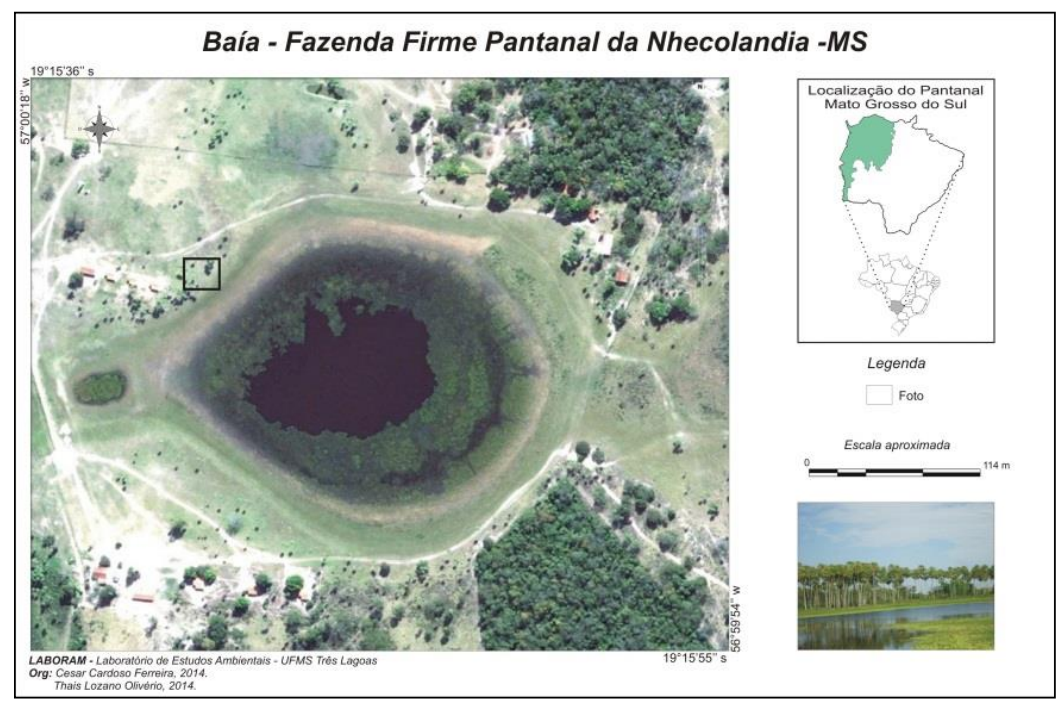

Figura 3 - Baía

\subsection{Análise dos dados}

Monteiro (1951) estudando o clima na antiga Região Centro-Oeste analisou o clima pantaneiro e utilizou como base os dados da estação meteorológica de Corumbá/MS, onde as temperaturas da média anual são de $24,9^{\circ} \mathrm{C}$, com temperaturas máximas em dezembro e fevereiro entre $27,2^{\circ} \mathrm{C}$ e $27,7^{\circ} \mathrm{C}$. A estação chuvosa inicia-se em novembro e a seca inicia-se em maio. A pressão no período da seca se eleva e as temperaturas baixam com média de $21^{\circ} \mathrm{C}$ em julho, a umidade cai, registrando em agosto 61\%. (Gradella 2005 Apud Monteiro 1951).

O experimento foi realizado em condições de tempo instáveis, durante os dias de coleta houve passagem de um sistema frontal no dia 23 e 24 de Julho de 2014 causando grande nebulosidade e queda de temperatura nas unidades de paisagens analisadas.

No registro do dia 22 de Julho, as temperaturas estavam elevadas, os ambientes estudados apresentaram pequenas diferenças entre si, mesmo assim, ficou evidente a maior amplitude térmica, do ar durante o dia na Praia da lagoa salina registrando às $9 \mathrm{~h} 23 \mathrm{C}^{\circ}$, às $15 \mathrm{~h} 32 \mathrm{C}^{\circ}$ e as $21 \mathrm{~h} 22,1 \mathrm{C}^{\circ}$, em quanto na Lagoa Salitrada $9 \mathrm{~h} 20,1 \mathrm{C}$, as $15 \mathrm{~h} 31,7 \mathrm{C}^{\circ}$ e as $21 \mathrm{~h} 25,1 \mathrm{C}^{\circ}$, na Baía apresentou temperaturas semelhante a Lagoa salitrada registrando as $9 \mathrm{~h} 20,3 \mathrm{C}^{\circ}$ as $15 \mathrm{~h} 31,7$ e as $21 \mathrm{~h} 25,1 \mathrm{C}^{\circ}$, durante o registro das $21 \mathrm{~h}$ houve uma inversão térmica nas unidades, registando a temperatura mais baixa na praia da lagoa Salina, e temperaturas mais elevadas na 
Lagoa Salitrada e Baía, considerando que ambiente sem cobertura vegetal da praia influenciou o ganho e perda de energia mais rápida e mais acentuada do que na nas unidades de paisagens vegetadas.

No registro do dia 23 de julho, uma frente fria atuou sobre o Estado de Mato Grosso do Sul, trazendo queda de temperatura, e alta nebulosidade para a região do Pantanal sul Mato-grossense. Nas unidades da paisagem de analise, a praia da lagoa salina no intervalo das $9 \mathrm{~h}$ temperatura foi de $13,2 \mathrm{C}$ com $94 \%$ umidade, na área da lagoa salitrada a temperatura foi de 24,3 e $94 \%$ de umidade e na Baía o registro foi de $24,4 \mathrm{C}^{\circ}$ e $91 \%$ de umidade. No intervalo das $15 \mathrm{~h}$ na praia da lagoa salina a temperatura foi de $24,9 \mathrm{C}^{\circ} \mathrm{com} 77 \%$ umidade, na área da lagoa salitrada a temperatura foi de 25,3 e $74 \%$ de umidade e na Baía o registro foi de $25,4 \mathrm{C}^{\circ}$ e $73 \%$ de umidade. No intervalo das $21 \mathrm{~h}$ na praia da lagoa salina a temperatura foi de 23,2 $\mathrm{C}^{\circ}$ com $85 \%$ umidade, na área da lagoa salitrada a temperatura foi de 23,7 e $83 \%$ de umidade e na Baía o registro foi de $23,5 \mathrm{C}^{\circ}$ e $90 \%$ de umidade, neste período houve queda de precipitação em media $18,03 \mathrm{~mm}$ nas unidades de análise.

No registro do dia 24 de Julho o sistema frontal continua atuando sobre a região, trazendo queda de temperatura e pancadas de chuva durante o dia. Nas unidades da paisagem de analise, a praia da lagoa salina no intervalo das $9 \mathrm{~h}$ temperatura foi de $12,8 \mathrm{C}^{\circ} \mathrm{com} 82 \%$ de umidade, na área da lagoa salitrada a temperatura foi de 13,5 e $92 \%$ de umidade e na Baía o registro foi de 13,3 C ${ }^{\circ}$ e $91 \%$ de umidade, durante o período da $01 \mathrm{~h}$ as $09 \mathrm{~h}$ houve queda de precipitação na Lagoa salitrada 39,9 mm e na Baía de 48,01 mm trazendo alto índice de unidade no ar, já na lagoa salina por problemas técnicos no pluviômetro, não obtivemos os dados. No intervalo das $15 \mathrm{~h}$ na praia da lagoa salina a temperatura foi de $14 \mathrm{C}^{\circ}$ com $85 \%$ umidade, na área da lagoa salitrada a temperatura foi de 14,2 e $86 \%$ de umidade e na Baía o registro foi de $13,3 \mathrm{C}^{\circ}$ e $85 \%$ de umidade. No intervalo das $21 \mathrm{~h}$ na praia da lagoa salina a temperatura foi de $12,7 \mathrm{C}^{\circ}$ com $93 \%$ umidade, na área da lagoa salitrada a temperatura foi de 13,1 e $85 \%$ de umidade e na Baía o registro foi de $13 \mathrm{C}^{\circ}$ e $84 \%$ de umidade.

No registro do dia 25 de Julho as temperaturas nas unidades de paisagem continuaram relativamente baixas, a praia da lagoa salina no intervalo das $9 \mathrm{~h}$ temperatura foi de $15,1 \mathrm{C}^{\circ}$ com $85 \%$ de umidade, na área da lagoa salitrada a temperatura foi de 12,3 e $81 \%$ de umidade e na Baía o registro foi de 12,1 C ${ }^{\circ}$ e $81 \%$ 
de umidade. No intervalo das $15 \mathrm{~h}$ na praia da lagoa salina a temperatura foi de 14 $\mathrm{C}^{\circ}$ com $85 \%$ umidade, na área da lagoa salitrada a temperatura foi de $15 \mathrm{C}^{\circ}$ e $78 \%$ de umidade e na Baía o registro foi de $15,1 \mathrm{C}^{\circ}$ e $81 \%$ de umidade, das $16 \mathrm{~h}$ as $18 \mathrm{~h}$ houve precipitação na Lagoa salitrada de 2,54 mm e na Baía de 2,03 mm, já na lagoa salina por problemas técnicos no pluviômetro, não obtivemos os dados. No intervalo das $21 \mathrm{~h}$ na praia da lagoa salina a temperatura foi de $13,5 \mathrm{C}^{\circ} \mathrm{com} 93 \%$ umidade, na área da lagoa salitrada a temperatura foi de 14,2 e $93 \%$ de umidade e na Baía o registro foi de $13,8 \mathrm{C}^{\circ}$ e $92 \%$ de umidade.

No registro dos dias 26 e 27 de Julho as temperaturas começaram a aumentar após a passagem da frente fria, no dia 26 a diferença entre todos as unidades foram em media $2 \mathrm{C}^{\circ}$ em todos os intervalos, já no dia 27 a diferença se estendeu para 5 $\mathrm{C}^{\circ}$ também em todos intervalos. No registro do dia 28 de Julho na praia da lagoa salina no intervalo das $9 \mathrm{~h}$ temperatura foi de $17,8^{\circ}$ com $99 \%$ umidade, na área da lagoa salitrada a temperatura foi de 18,3 e $94 \%$ de umidade e na Baía o registro foi de $17,3 \mathrm{C}^{\circ}$ e $97 \%$ de umidade. No intervalo das $15 \mathrm{~h}$ na praia da lagoa salina a temperatura foi de $27,1^{\circ}$ com $74 \%$ umidade, na área da lagoa salitrada a temperatura foi de 25,3 e $76 \%$ de umidade e na Baía o registro foi de 24,2 C ${ }^{\circ}$ e $79 \%$ de umidade. No intervalo das $21 \mathrm{~h}$ na praia da lagoa salina a temperatura foi de 20,4 $\mathrm{C}^{\circ}$ com $95 \%$ umidade, na área da lagoa salitrada a temperatura foi de $21 \mathrm{C}^{\circ}$ e $94 \%$ de umidade e na Baía o registro foi de 20,9 C e $94 \%$ de umidade.

Durante os dias de análise a queda de temperatura foi registrada em todos os pontos de amostragem, considerando a influencia de sistema frontal durante os dias de coleta. Assim, podemos considerar a vegetação, água e a ocupação do solo da área estudada como um fator de relevância no micro clima local. De tal modo, buscamos evidenciar os possíveis fenômenos que influenciam diretamente os elementos climáticos provocando uma nítida alteração sobre as unidades analisadas.

Podemos considerar que a área de praia da Lagoa, apresenta características climáticas mais acentuadas, pois é um ambiente que não habita indivíduos vegetais. A maior e menor temperatura na praia da lagoa salina se dá pelo fato de não haver cobertura vegetal e a radiação solar ser direta no solo arenoso da praia, tornando-se profundamente vulnerável a oscilação, com um micro clima instável, visto que a ausência de vegetação propicia uma alteração de gradiente bem visível, sobretudo 
na temperatura e evaporação, observando que a evaporação na área sem vegetação é superior às áreas que possuem vegetação, devido principalmente à incidência direta dos raios solares, sobretudo ao meio dia quando o Sol atinge o seu zênite, o que aumenta a capacidade de evaporação.

$\mathrm{Na}$ área da lagoa salitrada e Baía, os ambientes apresentaram características climáticas moderadas, é considerado um ambiente intermediário, na medida em que habita indivíduos vegetais, como gramíneas e arvores de grande porte de uma forma esparsa.

\section{CONCLUSÃo}

Através da investigação dos registros coletados em campo, constatamos que há diferença climática nas unidades de paisagem, em função de suas características distintas, porém como a região encontrava-se com o predomínio de um sistema frontal, sua influencia mostrou queda de temperatura, nos dias de análise. Os ambientes estudados apresentaram pequenas diferenças entre si, mesmo assim, ficou evidente a maior amplitude térmica do ar na praia da salina, enquanto na lagoa salitrada e Baía apresentou amplitude menor. No ambiente sem cobertura vegetal da praia ocorreu um ganho e perda de energia mais rápida e mais acentuada do que nas unidades mais vegetada.

Assim, considerando o evento climático ocorrido na sub-região do Pantanal da Nhecolândia, em específico, área da Fazenda Firme, a diferença microclimática não apresentou resultado muito acentuado, porém, quando levamos em consideração a proximidade e o tamanho das unidades, verificamos que os resultados apresentaram uma oscilação considerável. O microclima registrado em cada ambiente possibilitou estabelecer que a dinâmica atmosférica, os elementos das unidades da paisagem e a ocupação podem ser condições que alteram o microclima da diferentes unidades. 


\section{REFERENCIAS}

ASSINE, M. L. Sedimentação na Bacia do Pantanal Mato-Grossense, Centro-Oeste do Brasil. 2003. 106 f. Tese (Livre-Docência) - Instituto de Geociências e Ciências Exatas, Universidade Estadual Paulista, Rio Claro-SP, 2003.

ALVARENGA, Silvia Maria; BRASIL, Antonia Eloísa; DEL'ARCO, Diana Melo. Geomorfologia. In. Projeto Radambrasil. Levantamento de recursos naturais. Folha SF 21 Campo Grande: Rio de Janeiro, 1982.

GODOY FILHO, J. D., Aspectos Geológicos do Pantanal Mato-grossense e sua Área de Influência. In: Simpósio Sobre Recursos Naturais e Sócio-Econômico do Pantanal, 1. 1986, Corumbá - MS. Anais... Brasília - DF. EMBRAPA/CPAP, 1986. p 63-77.

GRADELLA, Frederico dos Santos. Comportamento térmico em unidades da Paisagem no Pantanal da Nhecolândia/MS-Brasil: estudo de caso na Fazenda Nhumirim/EMBRAPA/Pantanal. UFMS: Três Lagoas, 2005.

MONTEIRO, Carlos Augusto de Figueiredo. O estudo geográfico do clima. Cadernos Geográficos. n.1 (maio 1999). Florianópolis: Imprensa Universitária, 1999.

MONTEIRO, C. A. de F. Teoria e Clima Urbano. São Paulo: IGEOG/USP, 1976.

REZENDE FILHO, A. T. Variabilidade de salinidade de uma área em uma baía/vazante na Fazenda Nhumirim, Pantanal da Nhecolândia: estudo de um método cartográfico. (Especialização). UFMS/CPTL, Três Lagoas, 2003

SAKAMOTO, Arnaldo Yoso; QUEIROZ NETO, José Pereira de; FERNANDES, Ermínio; LUCATTI, Hebert M. Topografia de lagoas salinas e seus entorno no Pantanal da Nhecolândia/MS. In: Resumos do II Simpósio Sobre Recursos Naturais e Sócio - Econômicos do Pantanal: Manejo e Conservação. EMBRAPA/CPAP-UFMS: Corumbá, 1996.

SILVA, J.S.V. \& ABDON, M.M. 1998. Delimitação do Pantanal Brasileiro e suas sub-regiões. Pesquisa Agropecuária Brasileira 33:1703-1711

SILVA, Lenise Robles Borba. Microclima no Pantanal Sul-mato-grossense: análise do campo térmico em unidades da Paisagem da Nhecolândia (monografia de graduação). UFMS/CPTL. Três Lagoas, 2003.

ZAVATTINI, J. A. Dinâmica climática no Mato Grosso do Sul. Geografia. Rio Claro: IGCE/UNESP, 1992. v. 17(2), pp. 65-91.

ZAVATTINI, J. A. Estudos de clima no Brasil. Campinas/SP: Editora Alínea, 2004.

Imagens de Satélite Meteorológico GOES consultadas no site do Centro de Previsão do Tempo e Estudos Climáticos do Instituto Nacional de Pesquisas Espaciais (CPTEC/INPE)Disponível em: $<$ http://satelite.cptec.inpe.br/acervo/goes_anteriores.jsp> Acesso em: 27/05/2015

Cartas de Pressão ao Nível do Mar - Marinha do Brasil. Disponível em:

$<$ http://www.mar.mil.br/dhn/chm/meteo/prev/cartas/cartas.htm> Acesso em 27/05/2015 